\title{
PENGARUH BUDAYA ORGANISASI DAN LINGKUNGAN KERJA FISIK TERHADAP MOTIVASI KERJA KARYAWAN PADA PT. MUSTIKA RATU INTERBUANA DI DENPASAR
}

\author{
Nyoman Dwika Ayu Amrita ${ }^{1}$ \\ I Gusti Ayu Ketut Nataliani $^{2}$ \\ ${ }^{1}$ Fakultas Ekonomi Universitas Ngurah Rai, Denpasar \\ e-mail: geknataliani@gmail.com \\ ${ }^{2}$ Fakultas Ekonomi Universitas Ngurah Rai, Denpasar
}

\begin{abstract}
ABSTRAK
Penelitian ini bertujuan untuk mengetahui secara parsial dan simultan pengaruh Budaya Organisasi dan Lingkungan Kerja Fisik terhadap Motivasi kerja karyawan. Jumlah sempel yang diambil sebanyak 44 orang responden. Berdasarkan perhitungan diperoleh kesimpulan : Budaya organisasi dan lingkungan kerja fisik terbukti secara parsial berpengaruh Positif dan signifikan terhadap motivasi kerja karyawan pada PT. Mustika Ratu Interbuana di Denpasar dilihat dari analisis regresi linier berganda dimana setiap peningkatan 1 satuan budaya organisasi akan diikuti peningkatan motivasi sebesar 0,444 satuan dan setiap peningkatan 1 satuan lingkungan kerja fisik akan diikuti peningkatan motivasi sebesar 0,184 satuan dan hal ini diuji dengan analisis t -test dimana t-hitung yang dihasilkan Budaya Organisasi 8,069 dan lingkungan kerja fisik 2,301 lebih besar dari t- tabel 1,682 dan secara simultan, Budaya Organisasi dan lingkungan kerja Fisik juga berpengaruh positif dan signifikan terhadap Motivasi kerja karyawan dilihat dari hasil F-test dimana F-hitung 33,100 lebih besar dari F-tabel 3,23. Konstribusi variabel Budaya organisasi dan lingkungan kerja fisik terhadap variasi Motivasi kerja karyawan sebesar 62,8 persen sedangkan sisanya 37,2 persen adalah konstribusi faktor lain yang tidak diteliti. untuk meningkatkan Motivasi kerja karyawan PT Mustika Ratu Interbuana di Denpasar, sebaiknya manajemen menerapkan berbagai kebijakan Budaya Organisasi dan Lingkungan Kerja Fisik dengan upaya memberikan penghargaan jika menunjukan prestasi yang sesuai harapan sehingga motivasi kerja semakin meningkat.
\end{abstract}

Kata Kunci: Budaya Organisasi, Lingkungan Kerja Fisik dan Motivasi

\begin{abstract}
This study aims to determine the partial and simultaneous influence of Organizational Culture and Physical Work Environment on employee work motivation. The number of seals taken as many as 44 respondents. Based on the calculations obtained conclusion: Organizational culture and physical work environment proved to be partially positive and significant impact on employee motivation at PT. Mustika Ratu Interbuana in Denpasar seen from multiple linear regression analysis where every increase of 1 organizational culture unit will be followed by improvement of motivation equal to 0,444 unit and every increase 1 unit of physical work environment will be followed by improvement of motivation equal to 0,184 unit and this is tested by t-test analysis where t-arithmetic result of Organizational Culture 8,069 and physical work environment 2,301 bigger than t-table 1,682 and simultaneously, Organizational Culture and Physical work environment also have positive and significant effect to employee's Motivation seen from result F-test where F-hitung 33,100 greater than F-table 3.23. Contribution of variables Organizational culture and physical work environment to variation Employee work motivation of 62.8 percent while the remaining 37.2 percent is the contribution of other factors not examined. to improve the work motivation of employees of PT Mustika Ratu Interbuana in Denpasar, the management should apply various policies of Organizational Culture and Physical Work Environment with an effort to give awards if it shows achievement according to expectations so that the motivation of work is increasing.
\end{abstract}

Keywords: Organizational Culture, Physical Work Environment and Motivation 


\section{PENDAHULUAN}

Saat ini tidak dapat dipungkiri bahwa globalisasi telah menuntut banyak perubahan, perbaikan serta peningkatan kualitas perusahaan diberbagai bidang. Jika dihubungkan dengan sumber daya manusia perlu peningkatan mutu dan kemampuan tenaga kerja agar mampu mandiri dan bersaing. Diantara salah satu aspek yang berkenaan dengan sumber daya manusia yang harus di perhatikan oleh perusahaan atau organisasi adalah motivasi kerja.

Mengingat pentingnya motivasi kerja karyawan, maka untuk menciptakan karyawan yang memiliki motivasi kerja yang tinggi salah satu langkah yang dapat ditempuh oleh seorang pimpinan adalah dengan dengan memperhatikan faktor-faktor yang mempengaruhinya seperti budaya organisasi, dan lingkungan kerja fisik.

Penelitian ini dilaksanakan di PT. Mustika Ratu Interbuana di Denpasar yang merupakan perusahaan yang mendistribusikan produk jamu dan kosmetika dengan merk Mustika Ratu. PT. Mustika Ratu Interbuana di Denpasar memiliki karyawan sebanyak 175 orang yang dibagi beberapa bagian yaitu bagian gudang terdiri dari 25 orang, bagian pengecekan terdiri dari 25 orang, bagian paking terdiri dari 25 orang, bagian Sopir (Driver) terdiri dari 50 orang, bagian Pembantu sopir (Helper) terdiri dari 50 orang, sehingga ini tidak terlepas dari persoalan-persoalan berkaitan dengan budaya organisasi, lingkungan kerja fisik dan motivasi kerja.

Berdasarkan hasil penelitian awal di PT. Mustika Ratu Interbuana di Denpasar masih terjadi adanya permasalahan-permasalahan yang berkaitan dengan budaya organisasi, lingkungan kerja fisik, dan motivasi kerja karyawan.

Permasalahan berkaitan dengan budaya organsiasi pada PT. Mustika Ratu Interbuana di Denpasar adalah dalam melaksanakan tugas sering menunggu instruksi dari pimpinan padahal seluruh karyawan sudah mendapat pendelegasian tugas yang jelas sesuai dengan job masingmasing, tetapi masih belum sesuai dengan yang diharapkan. Permasalahan berkaitan dengan lingkungan kerja fisik PT. Mustika Ratu Interbuana di Denpasar antara lain: kondisi ruangan karyawan yang terlalu sempit, ruang gudang tidak tertata dengan rapi di mana letak peritem barang menurut kode produksi sulit dicari sehingga mengurangi efektivitas dalam bekerja dan suara truk-truk pengiriman sangat bising sehingga mengganggu konsentrasi karyawan saat beraktivitas.

Permasalahan berkaitan dengan motivasi PT. Mustika Ratu Interbuana di Denpasar antara lain: beberapa pegawai merasa keberadaannya tidak dihargai, hal ini terlihat dari tidak diikutsertakan dalam musyawarah dalam pengambilan keputusan, sehingga hal ini mengakibatkan adanya tingkat absensi yang melebihi target yaitu $3,22 \%$..

Berdasarkan kenyataan yang ada di PT. Mustika Ratu Interbuana di Denpasar, maka cukup relevan diadakan penelitian dengan judul :

"Pengaruh Budaya Organisasi dan Lingkungan Kerja fisik Terhadap Motivasi Kerja Karyawan pada PT. Mustika Ratu Interbuana di Denpasar". Berdasarkan dari uraian latar belakang tersebut, maka yang 
menjadi rumusan masalah dalam penelitian ini adalah :

a. Bagaimana pengaruh secara parsial budaya organisasi terhadap motivasi kerja karyawan pada PT. Mustika Ratu Interbuana di Denpasar?

b. Bagaimana pengaruh secara parsial lingkungan kerja fisik terhadap motivasi kerja karyawan pada PT. Mustika Ratu Interbuana di Denpasar?

c. Bagaimana pengaruh secara simultan budaya organisasi dan lingkungan kerja fisik terhadap motivasi kerja karyawan pada PT. Mustika Ratu Interbuana di Denpasar?

\section{METODE PENELITIAN}

Penelitian ini berlokasi pada PT. Mustika Ratu Interbuana di Denpasar. Varibel yang dapat di indenfikasi dalam penelitian ini adalah: Variabel Bebas (Independen Variable) Adalah merupakan variabel yang mempengaruhi atau yang menjadi penyebab berubahnya variabel terikat (variable dependen) (Sugiono, 2011:61). Dalam penelitian ini yang menjadi variabel bebas adalah budaya organisasi (X1) dan lingkungan kerja fisik(X2). Variabel Terikat (Dependen Variable) Adalah merupakan variabel yang dipengaruhi oleh variabel bebas (independen variable) (Sugiono, 2011:61). Dalam penelitian ini yang menjadi variabel terikat adalah motivasi kerja karyawan (Y).

Responden dalam penelitian ini adalah karyawan PT. Mustika Ratu Interbuana di Denpasar yang diambil dari jumlah sempel 44 karyawan. Selanjutnya dari sempel tersebut responden diambil secara Proporsional Random Sampling berdasarkan pada masing-masing bagian dan jawaban karyawan yang ada responden di ambil secara acak random.

\section{HASIL PEMBAHASAN}

Teknik analisis yang dipergunakan dalam penelitian ini adalah regresi linier berganda, determinasi dan pengujian hipotesis (uji $\mathrm{t}$ dan uji $\mathrm{F}$ ), dimana dalam penelitian ini perhitungannya menggunakan program IBM SPSS Statistics Version 20. Hasil perhitungan dari data-data tersebut dapat dilihat pada tabel 5.4 berikut ini. 
Tabel 5.4 Rekapitulasi Hasil Olahan IBM SPSS Statistics Version 20

\begin{tabular}{llcc}
\multicolumn{1}{c}{ Nama Variabel } & \multicolumn{1}{c}{$\begin{array}{c}\text { Koefisien } \\
\text { Regresi }\end{array}$} & t-test & $\begin{array}{c}\text { Koefisien } \\
\text { Beta }\end{array}$ \\
\hline Budaya Organisasi $\left(\mathrm{X}_{1}\right)$ & 0,444 & 8,069 & 0,789 \\
Lingkungan Kerja Fisik $\left(\mathrm{X}_{2}\right)$ & 0,184 & 2,301 & 0,225 \\
Konstanta & 0,476 & & \\
R & 0,786 & & \\
$\mathrm{R}^{2}$ & 0,628 & & \\
F Ratio & 33,100 & \\
Sig. F & 0,000 & \\
Regresi linier berganda & $\mathrm{Y}=0,476+0,444 \mathrm{X}_{1}+0,184 \mathrm{X}_{2}$ & \\
N & 44 & & \\
F-tabel $(5 \% ; 2 ; 41)$ & 3,23 & & \\
t-tabel $(5 \% ; 41)$ & 1,682 & & \\
\hline
\end{tabular}

a. Analisis Regresi Linier Berganda

Analisis

ini

dipergunakan untuk mengetahui perubahan moitvasi yang dipengaruhi oleh budaya organisasi dan lingkungan kerja fisik. Berdasarkan hasil perhitungan tersebut, diperoleh nilai konstanta a dan koefisien regersi $b_{1}$ dan $\mathrm{b}_{2}$, sebagai berikut:

$\mathrm{a}=0,476$

$\mathrm{b}_{1}=0,444$

$\mathrm{b}_{2}=0,184$

Berdasarkan nilainilai tersebut di atas, maka diperoleh persamaan regresi berganda sebagai berikut : Y $=0,476+0,444 \mathrm{X}_{1}+$ $0,184 X_{2}$. Berdasarkan persamaan tersebut, maka pengaruh budaya organisasi dan lingkungan kerja fisik terhadap motivasi kerja di PT. Mustika Ratu Interbuana di Denpasar dapat diartikan sebagai berikut :

1) Jika budaya organisasi $\left(\mathrm{X}_{1}\right)$ ditingkatkan, sedangkan lingkungan

kerja fisik $\left(\mathrm{X}_{2}\right)$

konstan atau tetap, maka perhitungannya akan menjadi

$\mathrm{Y}=0,476+0,444 \mathrm{X}_{1}+$ $0,184 X_{2}$

$\mathrm{Y}=0,476+0,444(1)+$ $0,184(0)$

$\mathrm{Y}=0,476+0,444$

$\mathrm{Y}=0,920$

Berdasarkan

perhitungan di atas, dapat dijelaskan bahwa jika budaya organisasi

ditingkatkan, sedangkan lingkungan kerja fisik konstan atau tetap, maka motivasi kerja karyawan di PT. Mustika Ratu Interbuana di Denpasar adalah sebesar 0,920 satuan atau dengan kata lain motivasi kerja meningkat sebesar 0,444 satuan.

2) Jika lingkungan kerja fisik

$\left(\mathrm{X}_{2}\right)$ 


$$
\begin{aligned}
& \text { ditingkatkan, } \\
& \text { sedangkan budaya } \\
& \text { organisasi }\left(\mathrm{X}_{1}\right) \\
& \text { konstan atau tetap, } \\
& \text { maka perhitungannya } \\
& \text { akan menjadi : } \\
& \mathrm{Y}=0,476+0,444 \mathrm{X}_{1}+ \\
& 0,184 X_{2} \\
& \mathrm{Y}=0,476+0,444(0)+ \\
& 0,184(1) \\
& \mathrm{Y}=0,476+0,184 \\
& \mathrm{Y}=0,660 \\
& \text { Berdasarkan } \\
& \text { perhitungan di atas, } \\
& \text { dapat dijelaskan } \\
& \text { bahwa jika lingkungan } \\
& \text { kerja fisik } \\
& \text { ditingkatkan, } \\
& \text { sedangkan budaya } \\
& \text { organisasi konstan } \\
& \text { atau tetap, maka } \\
& \text { motivasi kerja } \\
& \text { karyawan di PT. } \\
& \text { Mustika Ratu } \\
& \text { Interbuana di } \\
& \text { Denpasar adalah } \\
& \text { sebesar 0,660 satuan } \\
& \text { atau dengan kata lain } \\
& \text { motivasi kerja } \\
& \text { meningkat sebesar } \\
& 0,184 \text { satuan. }
\end{aligned}
$$

\section{c. Pengujian Hipotisis}

1) Analisis Uji t-test Analisa ini digunakan untuk mengetahui apakah koefisien regresi tersebut signifikan atau tidak.
a). Pengaruh Budaya
Organisasi
Terhadap Motivasi
Kerja Karyawan di
(1) Perumusan

Hipotesis

(a) Ho : $\beta_{1}=0$, berarti budaya organisasi tidak berpengaruh positif dan signifikan terhadap

\section{b. Analisis Determinasi}

Analisis ini digunakan untuk mengetahui besar kecilnya sumbangan variabel bebas budaya organisasi dan lingkungan kerja fisik terhadap motivasi kerja karyawan pada PT. Mustika Ratu Interbuana di Denpasar, yang dinyatakan dalam persentase.

Berdasarkan

perhitungan diperoleh nilai koefisien determinasi sebesar 0,628 , maka :

$$
\begin{aligned}
\mathrm{D} & =\mathrm{r}^{2} \times 100 \% \\
& =0,628 \times 100 \% \\
& =62,8 \%
\end{aligned}
$$

Bardasarkan hasil perhitungan determinasi diperoleh hasil $62,8 \%$ artinya budaya organisasi dan lingkungan kerja fisik memberikan sumbangan terhadap motivasi kerja karyawan sebesar $62,8 \%$ sedangkan sisanya $\quad 37,2$ disumbangkan oleh faktorfaktor lain yang tidak diteliti dalam penelitian ini.

$$
\begin{aligned}
& \text { PT. Mustika Ratu } \\
& \text { Interbuana di } \\
& \text { Denpasar. } \\
& \text { Pengujian } \\
& \text { hipotesis } \\
& \text { dilakukan dengan } \\
& \text { menggunakan } \\
& \text { langkah-langkah } \\
& \text { pengujiannya } \\
& \text { sebagai berikut : }
\end{aligned}
$$

motivasi kerja karyawan di PT. Mustika Ratu Interbuana di Denpasar.

(b) $\mathrm{Ha}$ $: \beta_{1}>0$, berarti budaya organisasi berpengaruh 
positif dan signifikan terhadap motivasi kerja karyawan di PT. Mustika Ratu Interbuana di Denpasar. (2) Penentuan Statistik Tabel

Pada tingkat keyakinan sebesar 95\%, tingkat kesalahan sebesar 5\% dan df (degrees of freedom $=$ derajat bebas) $=\mathrm{n}-\mathrm{k}-1$. Untuk $\mathrm{n}=44$ dan $\mathrm{k}=2$ maka $\mathrm{df}=44$ $2-1=41$, di mana nilai yang paling mendekati adalah 41 sehingga besarnya $\mathrm{t}$-tabel $=\mathrm{t}_{(\alpha, \mathrm{df})}$ yang dicari adalah $\mathrm{t}_{(5 \%, 41)}$ yang ditampilkan pada lampiran 7 adalah sebesar $\mathrm{t}$-tabel= 1,682 .

(3) Penentuan t-hitung
Berdasarkan tabel 5.4, t-hitung untuk budaya organisasi adalah 8,069.

(4) Kriteria pengujian Adapun kriteria pengujian hipotesisnya yaitu :

(a) Ho diterima apabila t-hitung $\leq \mathrm{t}-$ tabel

(b) Ho ditolak apabila t-hitung > ttabel

Untuk memudahkan penentuan penerimaan atau penolakan hipotesis yang diajukan, maka berikut disajikan gambar kriteria penerimaan atau penolakan hipotesis dengan uji-t seperti terlihat pada Gambar 5.1. di bawah ini.

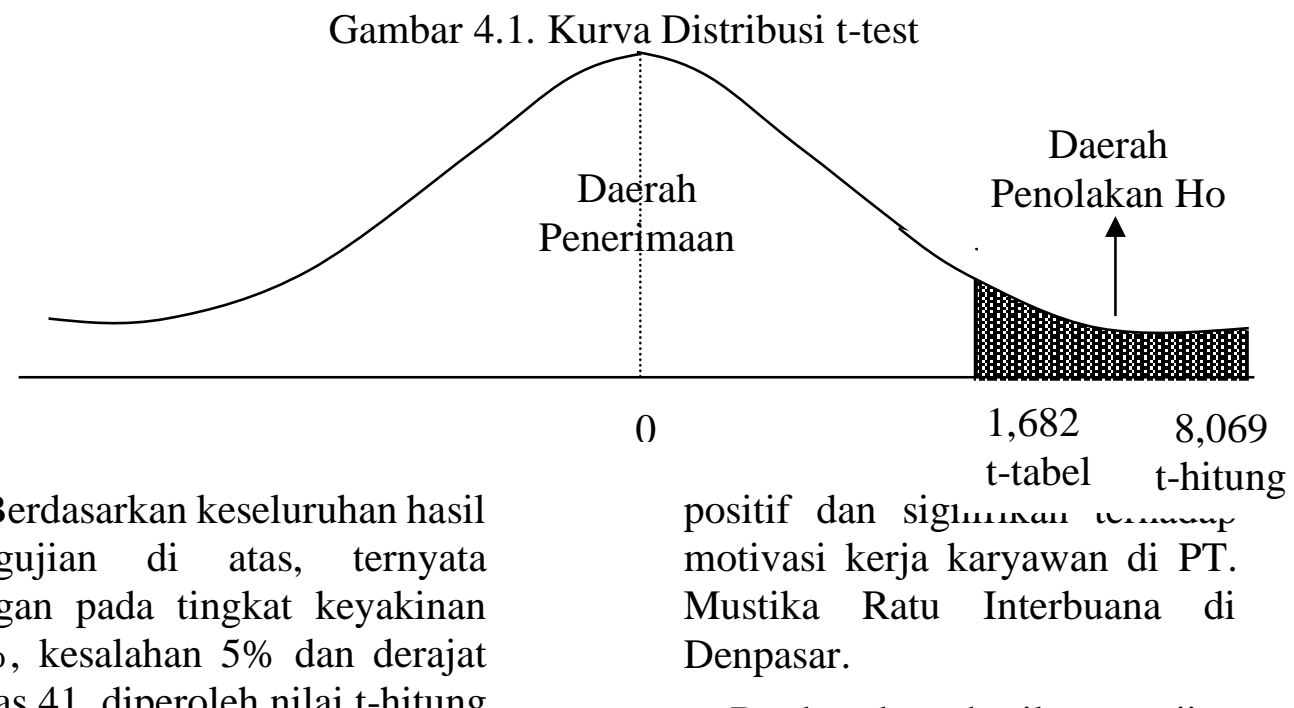

bebas 41 , diperoleh nilai t-hitung $=8,069$ dan nilai $\mathrm{t}$-tabel $=1,682$, sehingga kalau dibandingkan maka nilai t-hitung lebih besar dari nilai tabel dan t-hitung berada pada daerah penolakan Ho. Oleh karena itu, Ho ditolak dan $\mathrm{H}_{\mathrm{a}}$ diterima. Ini berarti bahwa budaya organisasi berpengaruh b) Pengaruh Lingkungan Kerja Fisik Terhadap Motivasi Kerja Karyawan di PT. Mustika Ratu Interbuana di Denpasar.

Berdasarkan hasil pengujian tersebut dapat dijelaskan bahwa budaya organisasi secara parsial berpengaruh positif dan signifikan terhadap motivasi kerja karyawan pada PT. Mustika Ratu Interbuana di Denpasar terbukti kebenarannya.

Pengujian hipotesis dilakukan dengan menggunakan langkahlangkah pengujiannya sebagai berikut : 
(1)

Perumusan

Hipotesis

(a) Ho: $\beta_{2}=0$, berarti lingkungan kerja fisik tidak berpengaruh positif dan signifikan terhadap motivasi kerja karyawan di PT. Mustika Ratu Interbuana di Denpasar.

(b) $\mathrm{Ha}: \beta_{2}>0, \quad$ berarti

lingkungan kerja fisik berpengaruh positif dan signifikan terhadap motivasi kerja karyawan di PT. Mustika Ratu Interbuana di Denpasar. (2) Penentuan

\section{Statistik Tabel}

Pada tingkat keyakinan sebesar 95\%, tingkat kesalahan sebesar $5 \%$ dan df (degrees of freedom $=$ derajat bebas $)=\mathrm{n}-\mathrm{k}-1$. Untuk $\mathrm{n}=44$ dan $\mathrm{k}=2$ maka $\mathrm{df}$ $=44-2-1=41$, dimana nilai yang paling mendekati adalah 41 sehingga besarnya $\mathrm{t}$-tabel $=\mathrm{t}_{(\alpha, \mathrm{df})}$ yang dicari adalah $t_{(5 \%, 41)}$ yang ditampilkan pada lampiran 7 adalah sebesar $\mathrm{t}$-tabel $=1,682$.

Penentuan $\mathrm{t}$ -

hitung

Berdasarkan Tabel 5.4, t-hitung untuk Lingkungan kerja fisik adalah 2,301.

Kriteria

pengujian

Adapun kriteria pengujian hipotesisnya yaitu :

(a) Ho diterima apabila t-hitung $\leq$ t-tabel

(b) Ho ditolak apabila t-hitung $>$ t-tabel
Untuk memudahkan penentuan penerimaan atau penolakan hipotesis yang diajukan, maka berikut disajikan gambar kriteria penerimaan atau penolakan hipotesis dengan uji-t seperti terlihat pada Gambar 4.2. di bawah ini.

Berdasarkan keseluruhan hasil pengujian di atas, ternyata dengan pada tingkat keyakinan 95\%, kesalahan 5\% dan derajat bebas 41 , diperoleh nilai $t-$ hitung $=2,301$ dan nilai $\mathrm{t}$-tabel $=$ 1,682, sehingga kalau dibandingkan maka nilai thitung lebih besar dari nilai tabel dan t-hitung berada pada daerah penolakan Ho. Oleh karena itu, Ho ditolak dan Ha diterima. Ini berarti bahwa lingkungan kerja fisik berpengaruh positif dan signifikan terhadap motivasi kerja karyawan di PT. Mustika Ratu Interbuana di Denpasar.

Berdasarkan hasil pengujian tersebut dapat dijelaskan bahwa lingkungan kerja fisik secara parsial berpengaruh positif dan signifikan terhadap motivasi kerja karyawan pada PT. Mustika Ratu Interbuana di Denpasar terbukti kebenarannya 


\section{Gambar 4.2 Kurva Distribusi t-test}

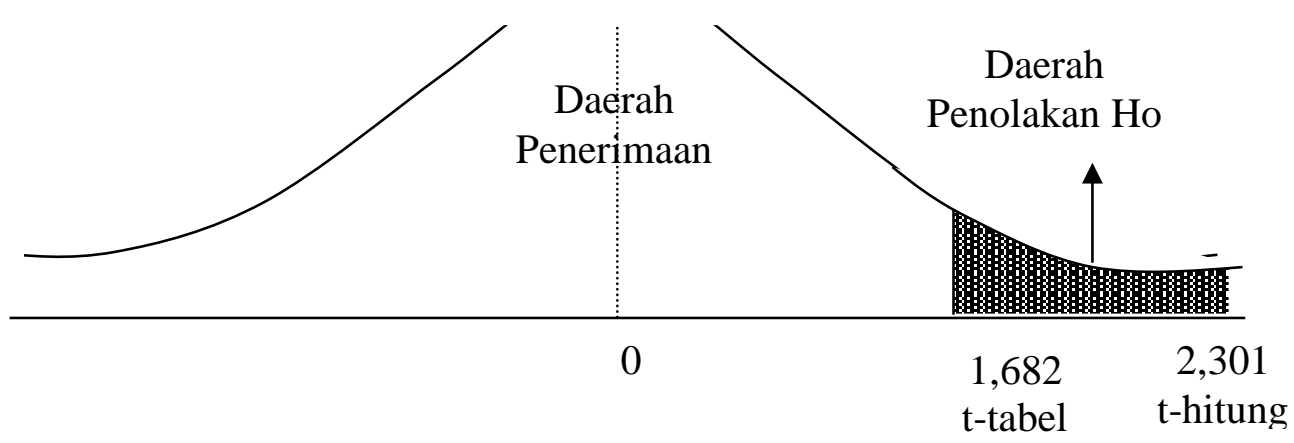

Berdasarkan keseluruhan hasil pengujian di atas, ternyata dengan pada tingkat keyakinan 95\%, kesalahan $5 \%$ dan derajat bebas 41 , diperoleh nilai t-hitung $=2,301$ dan nilai t-tabel $=1,682$, sehingga kalau dibandingkan maka nilai t-hitung lebih besar dari nilai tabel dan $\mathrm{t}$ hitung berada pada daerah penolakan Ho. Oleh karena itu, Ho ditolak dan Ha diterima. Ini berarti bahwa lingkungan kerja fisik berpengaruh positif dan signifikan terhadap motivasi kerja karyawan di PT. Mustika Ratu Interbuana di Denpasar.

Berdasarkan hasil pengujian tersebut dapat dijelaskan bahwa lingkungan kerja fisik secara parsial berpengaruh positif dan signifikan terhadap motivasi kerja karyawan pada PT. Mustika Ratu Interbuana di Denpasar terbukti kebenarannya.

2) Uji-F (F-test)

Digunakan untuk menguji keberartian koefisien korelasi secara

pengujian ini adalah sebesar 5\% $(\alpha<0,05)$ dengan dfn (degrees of freedom numerator $=$ derajat bebas pembilang) $\mathrm{k}$, dan dfd (degrees of freedom dominator=derajat bebaspenyebut) $\mathrm{n}-\mathrm{k}-1$. Untuk $\mathrm{k}=2$ serempak atau bersama-sama, maka dilakukan pengujian dengan menggunakan uji-F yang langkahlangkah pengujiannya adalah sebagai berikut :

a)

Formulasi hipotesis

(1) Ho : $\beta_{1}, \beta_{2}=0$, berarti budaya organisasi dan lingkungan kerja fisik tidak berpengaruh positif dan signifikan terhadap motivasi kerja karyawan di PT. Mustika Ratu Interbuana di Denpasar.

(2) Ha : $\beta_{1}, \beta_{2}>0$, berarti budaya organisasi dan lingkungan kerja fisik berpengaruh positif dan signifikan terhadap motivasi kerja karyawan di PT. Mustika Ratu Interbuana di Denpasar.

b) Penentuan Statistik

Tabel

Dalam pengujian ini digunakan $\mathrm{F}_{\text {tabel }}=\mathrm{F}_{(\alpha ; \mathrm{dfn} / \mathrm{dfd})} \alpha$ atau taraf kesalahan (level of significancy) yang dipakai dalam

dan $\mathrm{n}=44$, maka dfd $=44-2-1=41$ maka besarnya $F_{\text {tabel }}=(\alpha ;$ dfn/dfd $)$ yang dicari adalah $\mathrm{F}(5 \%, 2 / 41)$, yang pada Tabel $\mathrm{F}$ dalam lampiran 8 besarnya yaitu 3,23. 
c) Penentuan F-hitung

Berdasarkan hasil perhitungan diperoleh besarnya

F-hitung $=33,100$.

d) Kriteria Penerimaan/Penolakan Hipotesis

Adapun kriteria pengujian hipotesisnya yaitu :
(1) Ho diterima apabila F-hitung $\leq$ F-tabel

(2) Ho ditolak apabila F-hitung > F-tabel

Untuk lebih jelasnya, dapat dilihat pada gambar 5.3 kurva normal dibawah ini.

Gambar 5.3.Kurva Distribusi Normal Daerah Penerimaan dan Daerah Penolakan

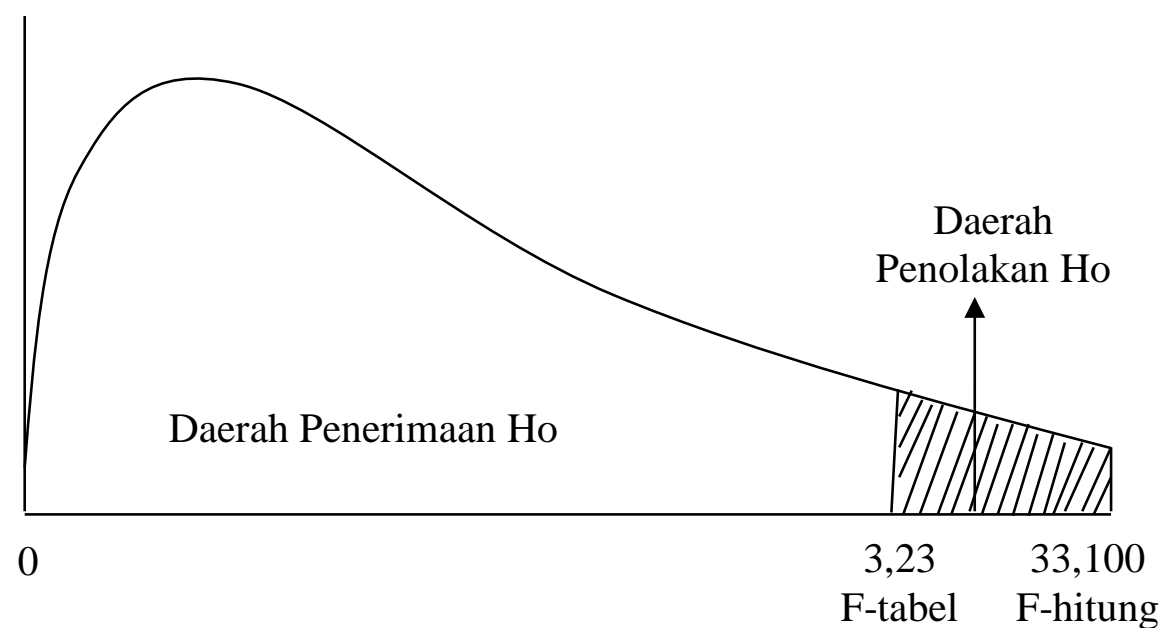

Berdasarkan keseluruhan hasil pengujian di atas, ternyata dengan tingkat keyakinan 95\%, kesalahan 5\% dan derajat bebas pembilang 2 dan derajat bebas penyebut 41 , diperoleh nilai F-hitung sebesar 33,100 dan nilai t-tabel sebesar 3,23, sehingga kalau dibandingkan maka nilai Fhitung lebih besar dari nilai F-tabel dan F-hitung berada pada daerah penolakan Ho. Oleh karena itu, Ho ditolak dan Ha diterima. Ini berarti budaya organisasi dan lingkungan

\section{Simpulan}

Berdasarkan rumusan masalah dan pembahasan hasil penelitian maka kerja fisik berpengaruh positif dan signifikan terhadap motivasi kerja karyawan di PT. Mustika Ratu Interbuana di Denpasar. Berdasarkan hasil pengujian tersebut, maka hipotesis yang menyatakan bahwa budaya organisasi dan lingkungan kerja fisik secara simultan berpengaruh positif dan signifikan terhadap motivasi kerja karyawan pada PT. Mustika Ratu Interbuana di Denpasar, terbukti kebenarannya.

kesimpulan yang dihasilkan dari penelitian ini adalah sebagai berikut : a. Terdapat pengaruh positif dan signifikan secara parsial dari budaya 
organisasi terhadap motivasi kerja karyawan pada PT. Mustika Ratu Interbuana di Denpasar. Hal ini didasari dari hasil analisis regresi berganda dimana setiap peningkatan 1 satuan budaya organisasi akan diikuti dengan peningkatan motivasi karyawan sebesar 0,444 satuan dan hal ini diuji dengan analisis t-test (uji t) dimana diperoleh nilai t-hitung untuk budaya organisasi sebesar 8,069 , dan nilai t-tabel untuk budaya organisasi sebesar 1,682, sehingga kalau dibandingkan maka nilai $\mathrm{t}$ hitung lebih besar dari nilai tabel dan t-hitung berada pada daerah penolakan Ho. Oleh karena itu, Ho ditolak dan $\mathrm{Ha}$ diterima. Ini berarti bahwa budaya organisasi secara parsial berpengaruh positif dan signifikan terhadap motivasi kerja karyawan di PT. Mustika Ratu Interbuana di Denpasar.

b. Terdapat pengaruh positif dan signifikan secara parsial dari lingkungan kerja fisik terhadap motivasi kerja karyawan pada PT. Mustika Ratu Interbuana di Denpasar. Hal ini didasari dari hasil analisis regresi berganda dimana setiap peningkatan 1 satuan lingkungan kerja fisik akan diikuti dengan peningkatan motivasi kerja karyawan sebesar 0,184 satuan dan hal ini diuji dengan analisis t-test (uji t) dimana diperoleh nilai t-hitung untuk Lingkungan kerja fisik sebesar 2,301, dan nilai t-tabel untuk lingkungan kerja fisik sebesar 1,682, sehingga

\section{Saran}

Berdasarkan kesimpulan yang telah dikemukakan diatas, maka saran - saran yang dapat penulis berikan sebagai bahan masukan bagi pihak perusahaan adalah sebagai berikut : kalau dibandingkan maka nilai thitung lebih besar dari nilai tabel dan t-hitung berada pada daerah penolakan Ho. Oleh karena itu, Ho ditolak dan $\mathrm{Ha}$ diterima. Ini berarti bahwa lingkungan kerja fisik secara parsial berpengaruh positif dan signifikan terhadap motivasi kerja karyawan di PT. Mustika Ratu Interbuana di Denpasar.

c. Terdapat pengaruh positif dan signifikan secara simultan dari budaya organisasi dan lingkungan kerja fisik terhadap motivasi kerja karyawan di PT.Mustika Ratu Interbuana di Denpasar. Hal ini didasari dari hasil analisis determinasi dimana diperoleh hasil $62,8 \%$ artinya budaya organisasi dan lingkungan kerja fisik memberikan sumbangan terhadap motivasi kerja karyawan sebesar $62,8 \%$ sedangkan sisanya $37,2 \%$ disumbangkan oleh faktorfaktor lain yang tidak diteliti dalam penelitian ini dan hal ini diuji dengan analisis F-test (uji F) dimana diperoleh nilai F-hitung sebesar 33,100 , dan nilai F-tabel sebesar 3,23, sehingga kalau dibandingkan maka nilai F-hitung lebih besar dari nilai F-tabel dan F-hitung berada pada daerah penolakan Ho. Oleh karena itu, Ho ditolak dan Ha diterima. Ini berarti budaya organisasi dan lingkungan kerja fisik secara simultan berpengaruh positif dan signifikan terhadap motivasi kerja karyawan di PT. Mustika Ratu Interbuana di Denpasar.

Untuk meningkatkan motivasi karyawan PT. Mustika Ratu Interbuana di Denpasar, sebaiknya manajemen menerapkan berbagai kebijakan budaya organisasi dan lingkungan kerja fisik dengan upaya yang dapat dilakukan misalnya 
memberikan karyawan penghargaan jika menunjukan prestasi yang sesuai dengan harapan dan mengikutsertakan karyawan dalam musyawarah pengambilan keputusan sehingga motivasi kerja karyawan semakin meningkat, serta menciptakan lingkungan kerja fisik yang lebih baik seperti penataan

\section{REFERENSI}

Akbar, Purnomo Setiady dan Husaini Usman.2006. Pengantar statistik. Bumi Aksara.

Arep, Ishak dan Hendri Tanjung. 2003.

Manajemen sumber daya manusia. Universitas Trisakti: Jakarta.

Arikunto Suharsimi. 2006. Prosedur Penelitian Suatu Pendekatan Praktis. Penerbit Rineka Cipta, Jakarta.

Basu swasta dan Ibnu Sukotjo. Pengantar bisnis modern. Edisi Ketiga 2002, Liberty: Yogyakarta

Bambang, Kusriyanto. 2008. Meningkatka produktivitas karyawan. Pustaka Binaman Pressindo: Jakarta

C.S.T Kansil, Christine. S.T. Kansil, Bagian (II). 2001 Hukum Perusahaan Indonesia Bagian 2. PT. Pratnya Paramita, Jakarta.

Fahmi Irham, 2010. Manajemen Kinerja Teori dan Aplikasi. Penerbit Alfabeta: Bandung.

Hasibuan SP. Malayu. 2007. Manajemen Sumber Daya Manusia. Edisi Revisi, Bumi Aksara: Jakarta. barang di gudang lebih ditata dengan rapi menurut peritem barang dan kode produksi sehingga efektivitas dalam bekerja lebih meningkat serta meningkatkan keamanan kerja karyawan sesuai dengan standar keamanan dan keselamatan keria sehingga karyawan merasa keaman kerjanya terjamin .

Hendrianti. 2014. Pengaruh Budaya Organisasi Dan Lingkungan Kerja Terhadap Motivasi Kerja Karyawan Pada PT. Badjatex Bandung, Jurnal Administrasi Bisnis (JAB), Vol.2, No. 3. Oktober 2014.

Junaidi. 2010. Table Distribusi $t$ dan

Distribusi F dengan Taraf

Signifikan 5\% (0,05). Diakses

14 April 2010,

(http://junaidichaniago.wordpres s.com).

Mathis Robert L. \& Jackson John H.. 2005. Manajemen Sumber Daya Manusia, Penerbit Salemba Empat.

Mangkunegara Anwar Prabu. 2009. Evaluasi Kinerja SDM. Penerbit Refika Aditama: Bandung.

2011. Manajemen Sumber Daya Manusia Perusahaan. Remaja Rosdakarya Offset: Bandung

Manulang M, 2010. Manajemen Personalia. Aksara Baru: Jakarta.

Nitisemito Alex S, 2010. Manajemen Personalia (Manajemen Sumber Daya Manusia). Penerbit Ghalia: Jakarta.

Novi Permata Sari. 2013. Pengaruh budaya organisasi dan lingkungan kerja fisik terhadap 
Pengaruh Budaya Organisasi Dan Lingkungan Kerja Fisik Terhadap Motivasi Kerja Karyawan Pada PT. Mustika Ratu Interbuana Di Denpasar

motivasi kerja Pegawai PDAM

Kabupaten Kudus. Vol.1, 2 Oktober 2013

Priansa Donni Juni dan Garnida Agus. 2013.Manajemen Perkantoran (Efektif, Efisien dan Profesional).

Cetakan ke-1, Alfabeta, Bandung Rangkuti Freddy. 2008. Business Plan.

Gramedia Pustaka Utama, Jakarta.

Riduwan dan Sunarto, 2011, Pengantar Statistika Untuk Penelitian : Pendidikan, Sosial, Komunikasi, Ekonomi dan Bisnis, Alfabeta, Bandung.

Robbins P. Stephen, 2006, Teori Organisasi Struktur, Desain \& Aplikasi, Edisi 3, Penerbit Arcan, Jakarta.

Sedarmayanti, 2009, Sumber Daya Manusia dan Produktivitas Kerja, CV, Mandar Maju, Bandung

Siagian Sondang P., 2008, Manajemen sumber daya manusia (Edisi Revisi). Penerbit Bumi Aksara

Simamora Henry, 2007, Manajemen Sumber Daya Manusia, Edisi 3, Cetakan 1, Bagian Penerbitan STIE YKPN, Yogyakarta.

Sugiyono, 2012, Statistika Untuk Penelitian, Cetakan Ke-21, Penerbit CV. Alfabeta, Bandung.

Sunyoto Danang dan Burhanudin. (2011. Perilaku Organisasi. Cetakan 1, CAPS, Yogyakarta.

Utama Mudiartha. 2007. Manajemen Sumber Daya Manusia. Denpasar: Universitas Udayana.

Usman Husaini, 2013, Manajemen, Teori, Praktik, dan Riset Pendidikan, Edisi 4, Bumi Aksara, Yogyakarta.

Wiratama R, Mukzam MD dan Uhana I, 2015, Pengaruh Lingkungan Kerja Fisik dan Lingkungan Kerja Non Fisik Terhadap
Motivasi Kerja Pegawai (Studi Pada Pegawai Kantor Pelayanan Kekayaan Negara dan Lelang Malang). Jurnal Administrasi Bisnis (JAB), Vol.27, No. 1. Oktober 2015.

Wuradji. 2008. The Educational Leadership (Kepemimpinan Transformasional), Gama Media: Yogyakarta. 